\title{
Legality of Autonomous Weapons Systems and their Implications on Existing International Humanitarian Law Principles Approach: New Haven School of International Legal Theory
}

Sai Venkatesh*

DOI: $10.21827 / 5 \mathrm{~d} 5141 \mathrm{e} 815 \mathrm{f} 80$

\begin{abstract}
Keywords
AUTONOMOUS WEAPONS; NEW HAVEN APPROACH; INTERNATIONAL HUMANITARIAN LAW
\end{abstract}

\begin{abstract}
The objective of this paper is to legally analyze the issues surrounding the use and regulation of Autonomous Weapons Systems (AWS) and their implications on the existing principles of International Humanitarian Law (IHL). The research and mode of approach towards this issue will be directed in consonance with the New Haven School of International Legal Thought. The paper will begin by defining the terms 'AWS' and 'New Haven school' for the purpose of this study. Subsequently, it will highlight the various notable issues of contention with relation to existing principles of IHL. In doing so, the paper will earmark these issues under the scope of the New Haven method and conclude exclusively to that school of international thought.

In its conclusion, this paper will emphasize the need for AWS in today's world, and how regulation, rather than prohibition, would be the ideal solution towards addressing the conundrum of their legality. It will also distinguish the key elements of the New Haven school and how these were directly incorporated into this paper so as to arrive at the predicated resolution, emphasizing the need for legality of AWS to attain world peace and order.
\end{abstract}

\section{Introduction}

It is no secret that today the international community faces a conundrum regarding the regulation and legality of Autonomous Weapons Systems (AWS). On one hand, most States, civil society organizations and people across the world have called for an outright ban on the use of any fully automated weapons (FAWs) in times of war, ${ }^{1}$ considering the grave nature of their operation (whereby there is no human control, implying a regime of non-accountability). However, while the concern over a lack of responsibility for the acts of these machines takes the limelight, there is still active work being done in relation to

\footnotetext{
Sai Venkatesh, Adv. LL.M in Public International Law (2019) (Leiden) sai.sathyanarayanan12@gmail.com.

Campaign to Stop Killer Robots <http://perma.cc/BYN8-YMQP]> accessed 12 May 2019.
} 
progress in this line of technology, ${ }^{2}$ albeit only by powerful, developed nations. This boils down to States acquiescing to the not-so-distant future, where they see the extreme likelihood of robots taking over human warfare and changing the dynamics of International Humanitarian Law (IHL) as we know it. This is not only affecting our existing legal and moral framework but creating an atmosphere of social change.

This has always been the case. War is an ever-evolving aspect of society, as can be evidenced through history. Jus in bello was never just a mere legal aspect distinctive from the policymakers behind it, as it addressed many different actors including combatants, civilians, States and even civil society groups. The commonality amongst all of them was their fight to ensure the achievement of the community goal of peace, with primary consideration towards human life and dignity.

Mankind has always adapted and evolved in a manner that endeavors to ensure efficiency in war and the achievement of the ultimate goal of peace, with the minimal possible loss. It is at this juncture that AWS take center stage. As can be seen, there exists no legal regimen for automated weapons and their use, considering the nature of this technology is still at its infancy. ${ }^{3}$ However, prior to that, we must answer the key question of what Autonomous Weapons Systems are and whether they are in use already.

\section{Definition of AWS}

Before turning to the law, it is necessary to frame the issue and define it. According to the International Committee of the Red Cross (ICRC), fully autonomous weapons systems are defined as 'any weapon system with autonomy in its critical functions-that is, a weapon system that can select (search for, detect, identify, track or select) and attack (use force against, neutralize, damage or destroy) targets without human intervention. ${ }^{4}$ This definition does not include human in the loop (or) human on the loop weapon systems which are already in use today. ${ }^{5}$ For the purpose of this study, the focus will adhere to FAWs, as defined by the ICRC.

Therefore, from the above definition, the crux of full autonomy is a capability to identify, target, and attack a person or object without human interface. In short, FAWs require no human input. Once they have been activated, they possess the power to attack of their own accord. This creates a rippling effect in the arena of international law, more specifically that of war-time regulation, or IHL. Who would be responsible for the acts of these machines? Can there still be a legal framework for war if humans are replaced?

\section{I.I New Haven Approach to International Law}

Jeffrey Thurnher, 'The Law That Applies to Autonomous Weapons Systems' (2013) 17 American Society of International Law Insights 4.

John Lewis, 'The Case for Regulating Fully Autonomous Weapons' (2015) 124 Yale Law Journal 1309, 1312. Law' (2017) UNODA Occasional Papers, No 30, 5. 
Legality of Autonomous Weapons Systems and their Implications on Existing International Humanitarian Law Principles Approach:

New Haven School of International Legal Theory $\mathbf{1 2 6}$ The New Haven School is a policy-oriented approach to international law, pioneered by Myres S Dougal, Harold D Lasswell and Michael W Reisman. ${ }^{6}$ According to this theory of international law, the legal system is principally based on sociological choices made in furtherance of any given policy. It is an interdisciplinary study of sociological elements and their direct impact on law and policy. The primary jurisprudential and intellectual tasks are the prescription and application of policy in ways that maintain community order and simultaneously achieve the best possible approximation of the community's social goals. ${ }^{7}$ Rather than being just a set of rules, law is a policy-oriented process of decision making; it is embedded in society and its goal is to promote values, in particular human dignity. ${ }^{8}$

Through the course of the paper, I will seek to highlight the legality of AWS through the lens of this school of international law, by drawing tenets to various existing IHL principles. This paper will also discuss the possible extension of the existing legal framework to accommodate the use of these weapons in order to achieve society's common goals of world peace and order.

\section{Objectives of War: Development of Society, War and Peace}

From a policy-oriented approach to legality, the need for AWS is of prime importance. The battlefield tempo outpaces a soldier's ability to make rational decisions in combat. To eliminate mishaps that stem from the same, it is imperative to look at other forms of intelligent, autonomous decision-making in the conduct of war. ${ }^{9}$ AWS can reduce the number of lives lost in combat, access areas otherwise inaccessible or dangerous and enhance force multiplication capabilities (ie referring to a factor or a combination of factors that give personnel or weapons the ability to accomplish greater things than without it). ${ }^{10}$

It is suggested that continued advances in autonomy will result in a reduction in atrocities. ${ }^{11}$ AWS solves the problem of 'scenario fulfilment'- a phenomenon whereby humans in stressful situations neglect or distort new information to fit their pre-existing beliefs. Therefore, AWS are an ethical imperative since they are invulnerable to patterns of premature cognitive closure. ${ }^{12}$

The ultimate goal of any armed conflict is to maintain or restore peace and world order. To achieve this goal without causing egregious violations of human rights, it is

BS Chimni, The Policy-Oriented or New Haven Approach to International Law: The Contributions of Myres $S$ Dougal and Harold Lasswell (Cambridge University Press 2017) 104-178.

Michael Reisman, 'The View from the New Haven School of International Law' (1992) Faculty Scholarship Series 867.

Andrea Bianchi, International Law Theories: An Inquiry Into Different Ways of Thinking (OUP 2016) Ch 5. Ronald Arkin, 'The Case for Ethical Autonomy in Unmanned Systems' (2010) 9 Journal of Military Ethics 4, 332. US Department of Defence, Autonomy in Weapon Systems (21 November 2012) (Directive)USD(P) $3000.09,92$. Robot Laboratory. 
necessary to comply with the legal framework established for conducting lawful armed conflict. Nevertheless, this would still involve inevitable human casualties, as humans are the main actors in any war or conflict. How would conflict eliminate the human aspect of war and the violence that ensues through such a struggle? A military objective may be attacked under the condition that, to attain the advantage sought, the attack is the least intrusive option available, with the minimal possible collateral damage.

It is under this hypothesis that AWS could signal the end of war as we know it and, more importantly, ensure the preservation of human dignity and life. The introduction of machines into armed conflict will reduce the involvement of humans. The retaliating force, whether it be a State or any other armed opposition group, will realize the threat they face, and the entire purpose of their struggle will come into question.

Through the years, what we have come to observe is that, with the advancement of weaponry, there seems to be greater reluctance to engage in conflict. In fact, we live in increasingly peaceful times. On average, fewer humans are experiencing violence today than ever before ${ }^{13}$ and there are fewer and less violent armed conflicts than has previously been seen. ${ }^{14}$ At the same time, warfare capabilities are growing and to be able to stay ahead of this curve requires the advancement and use of newly developed weapons.

It is, however, imperative to note that the call for development and legality of FAWs does not imply a reduction in accountability for violations of the laws of war. Rather, it is suggested that it would create a larger sense of accountability, as the use of FAWs has positive effects not only on the conduct of armed conflict but on the greater good of the human race.

\section{Conformity with International Humanitarian Law Principles}

The development or creation of any weapon should be done in accordance with the law of armed conflict (LOAC). With specific reference to AWS, their development and use would be required to conform to the core principles of IHL, namely distinction, proportionality, humanity and military necessity. ${ }^{15}$ Under Article 36 of Additional Protocol I to the Geneva Conventions of 1949 (Additional Protocol I), ${ }^{16}$ States must review new weapons systems to ensure that they are not indiscriminate in nature or likely to cause unnecessary injury. ${ }^{17}$

\section{III.I Proportionality}

Steven Pinker, The Better Angels of Our Nature: Why Violence Has Declined (Penguin Books 2012).

Joshua Goldstein, Winning the War on War: The Decline of Armed Conflict Worldwide (Penguin Publications 2011).

Greogory Noone and Diana Noone, 'The Debate over Autonomous Weapons Systems' (2015) 47 Case Western Journal of International Law 1, 28.

Protocol Additional to the Geneva Conventions of 12 August 1949 and Relating to the Protection of Victims of International Armed Conflicts (adopted 8 June 1977, entered into force 7 December 1978) 1125 UNTS 3 (Protocol I) art 36.

Jeffrey Thurnher, 'The Law that Applies to Autonomous Weapon Systems' (2013) 17 American Society of International Law Insights <www.asil.org/insights/volume/17/issue/4/law-applies-autonomousweapon-systems> accessed 12 May 2019. 
Legality of Autonomous Weapons Systems and their Implications on Existing International Humanitarian Law Principles Approach:

New Haven School of International Legal Theory 128 The proportionality principle will not be violated by AWS due to the existence of 'collateral damage estimate methodology' (CDEM). This is a procedure that takes several factors into account, such as the precision of weaponry and the probability of civilian presence near the target. If the probability of collateral damage is higher, the required level of command approval for AWS can also be programmed as higher, producing reliable results. ${ }^{18}$ Since the standard of assessing the proportionality of an attack is 'reasonableness', any assessment of proportionality must be based on information reasonably available at the time of attack. It is only logical that the same standard be applied to AWS.

\section{III.II Distinction}

Distinction is operationalized in a number of rules, the two most fundamental being the customary law prohibitions on making civilians and civilian objects the object of an attack. ${ }^{19}$ These rules are codified in Articles 51(2) and 52(1) of Additional Protocol I respectively. Evidently, this implies that it would be unlawful to use AWS to directly attack civilians or civilian objects. That is the case for all forms of weaponry, and thus this argument against the use of AWS must be ignored as a red herring. ${ }^{20}$

This issue is of specific interest in relation to the element of doubt. Where an issue arises regarding the status of an individual in an armed conflict, Article 50(1) of Additional Protocol I codifies the presumption that the said individual must be immune from attack. The factor of doubt is to be considered in terms of human reasonableness and to translate it to automated weapons systems therefore poses an apparent challenge.

It is at this juncture that the regulation of AWS can levy a higher sense of accountability for an attack made by a FAW. Further developments can be made, such as establishing a higher threshold for the deployment of AWS.

\section{III.III Martens Clause \& Humanity}

Research suggests that AWS could lessen the effects of war. This follows the reasoning that, where a soldier might be forced to make lethal defensive decisions, the AWS might be in a position to incapacitate instead of kill or be programmed not to 'prioritize their continued existence', ${ }^{21}$ thereby postponing the use of force and giving effect to the Martens Clause (ensuring that an individual is protected by the principles of humanity when laws of war are inapplicable). ${ }^{22}$ Arguments for AWS development claim that it can reduce human casualties, collateral damage and war crimes by making war less inhumane through lessening the human element of warfare. ${ }^{23}$ That is to say, AWS may perform better than humans because when combatants do violate IHL, it is usually for one or more

Schmitt (n 5) 19.

Schmitt (n 5) 15.

Noone (n 15) 29.

P Lin and others, Autonomous Military Robotics: Risks, Ethics and Design (prepared for the US Department of Navy, Office of Naval Research, 2008) 52.

Rupert Ticehurst, 'The Martens Clause and the Laws of Armed Conflict' (1997) 317 International Review of the Red Cross.

Arkin (n 9) 332-339. 
of several reasons, among which are fear, anger, frustration, revenge, stress, and selfpreservation. ${ }^{24}$

This rationale is identical to that which highlights the effectiveness of Unmanned Aerial Vehicles (UAVs or 'drones') in complying with IHL. UAV operators do not have self-preservation concerns forcing them to make a split-second decision on whether or not to pull the trigger. They have the ability to follow their target and acquire more information from multiple sources that will allow them to make the best decision possible. ${ }^{25}$

Considering the uncertainty inherent in armed conflict and the cataclysmic disasters during war that can result from human error, a policy-oriented approach based on decision-making that aims to maintain human dignity can possibly be the solution in the future.

\section{III.IV Accountability}

This paper analyzes the issue of the legality of AWS from the basic premise that the purpose of IHL is to minimize harm as understood in terms of suffering-primarily the suffering of civilians, but also the suffering of combatants. ${ }^{26}$ Arguments have been made that armed conflict 'is about committing evils and choosing between evils' ${ }^{27}$

While the 'autonomous' nature of FAWs appears to distance decision-makers from the harms they inflict, commanders remain responsible for the initial use of FAWs. The mere fact that a human might not be in control of a particular engagement does not mean that no human is responsible for the actions of the autonomous weapon system. ${ }^{28} \mathrm{~A}$ commander must give the order to deploy a FAW and set the parameters of its use. The use of AWS does not take away responsibility from humans but in fact increases the possibility of holding humans accountable for war crimes. By way of giving the order and overseeing the operation of the FAW, the commander by no means absolves him- or herself of responsibility for the actions of the weapon system. In assessing accountability, focus must be shifted from the immediate loop of the targeting decision to the 'wider loop', where there is always human involvement in the activation process. ${ }^{29}$ Accountability

Ryan Tonkens, ‘The Case Against Robotic Warfare: A Response to Arkin' (2012) 11 Journal of Military Ethics 149, 152-155.

Michael Schmitt, 'Unmanned Combat Aircraft Systems (Armed Drones) and International Humanitarian Law: Simplifying the Oft Benighted Debate' (2012) 30 Boston University International Law Journal 595, 597.

Eric Posner, 'A Theory of the Laws of War' (2003) 70 University of Chicago Law Review 297, 299-300; Michael Schmitt, '21st Century Conflict: Can the Law Survive?' (2007) 8 Melbourne Journal of International Law 443, 445.

Gabriella Blum, 'The Laws of War and the "Lesser Evil"' (2010) 35 Yale Journal of International Law 1,39 .

William Fenrick, 'The Prosecution of International Crimes in Relation to the Conduct of Military Operations', in Terry Gill and Dieter Fleck (eds), The Handbook Of The International Law Of Military Operations (OUP 2010), 501-505.

UNGA 'Report of the Special Rapporteur on Extrajudicial, Summary or Arbitrary Executions, Christof Heynes' (9 April 2013) A/HRC/23/47, para 77. 
Legality of Autonomous Weapons Systems and their Implications on Existing International Humanitarian Law Principles Approach:

New Haven School of International Legal Theory 130 could also be assigned in advance, ${ }^{30}$ and a requirement introduced to install recording devices that would enable transparency, reinforcing the credibility of IHL. ${ }^{31}$

\section{Conclusion}

This paper has set forth a foundational argument for the legality of AWS, through the lens of the New Haven Approach to International Law. Three key elements ${ }^{32}$ of this approach separate it from the clutches of a positivist or realist structure, namely:

\section{IV.I Decision-Making Phase}

This is where a decision can be taken that fosters social values which are worthy of protection. Such values will also be used as benchmarks to judge the appropriateness of the decision. In the instant case, the social value under protection is that of human life and dignity and, in consequence, the emphasis on peace over war. I am under the strong conviction that, by allowing for the creation of a legal regime for AWS, both these objectives can be accomplished.

\section{IV.II Emphasis on Contextuality}

Another important aspect of the New Haven School is that any decision must take into account a number of factors, which include the accumulated trend of past decisions, the institutional and temporal aspects of a situation and the values and goals by which one should be guided and pursue. Under this pretext, our history of war and its evolution have shown a transcendence in the use of weaponry, from rudimentary tools such as bows and arrows, to ammunition and long-range guns, to the use of bombs and distant targeting mechanisms. Throughout, the goal has always been to have the upper hand in an armed conflict and to be able to cause maximum harm to the enemy while facing minimal suffering. The use of AWS would accomplish that goal and satisfy the condition based on contextuality.

\section{IV.III Decision Must Presuppose a Policy Choice}

As stated by Gerald Fitzmaurice and Percy Spenders in their joint dissenting opinion in the South West Africa cases, "law cannot just be found "out there". ${ }^{33}$ It involves a process of choice between different arguments based on legal plausibility, and the New Haven School provides a methodology whereby such decisions can be evaluated.

On this premise, the entire argument regarding the legality of AWS can be summarized insofar as the urge towards a push for regulation, rather than prohibition, of AWS is concerned. Based on an interdisciplinary pretext, the consequences of such a legal

Ronald Arkin, ‘The Robot Didn't Do it: A Position Paper for the Workshop on Anticipatory Ethics, Responsibility and Artificial Agents' (University of Virginia 2013) 1.

M Sassòli, 'Autonomous Weapons and International Humanitarian Law: Advantages, Open Technical Questions and Legal Issues to be Clarified' (2014) 90 International Law Studies of US Naval War College.

Bianchi (n 8) 96.

South West Africa Cases (Ethiopia v. South Africa; Liberia v. South Africa)(Preliminary Objections, Judgment) [1962] ICJ Rep 319 Joint dissenting opinion of Sir Percy Spender and Sir Gerald Fitzmaurice 465, 466. 
131 GroJIL 7(1) (2019), 124-131

regime backed by sound policy measures may result in the following circumstances:

A. A complete end to war.

If war transforms from an act of actively killing human adversaries into an act of tactical and strategic combat engagement of warfare machinery, the utility of war might diminish.

Moral improvements in the battlefield:

B. As mentioned above, the reduction of human involvement in war may lead to the elimination of all biases and errors prone to mankind.

It is true that these would not be the only ramifications of war with FAWs, as there are reasonable grounds to expect that the threshold of war may decrease alongside a plausible increase in the abuse of power by powerful nations against their powerless counterparts. These consequences are overshadowed by the presence of existing legal regimes to govern armed conflict as well as the commitment to an overall community goal of maintaining peace and order. Therefore, regulation of legality rather than an outright prohibition can position the world towards achieving such an objective.

*

www.grojil.org 